\title{
Dietary calcium intake and the risk of colorectal cancer: a case control study
}

\author{
Changwoo Han ${ }^{1}$, Aesun Shin ${ }^{1 *}$, Jeonghee Lee ${ }^{2}$, Jeeyoo Lee ${ }^{1,5}$, Ji Won Park ${ }^{3,4}$, Jae Hwan Oh and Jeongseon Kim²
}

\begin{abstract}
Background: High intake of dietary calcium has been thought to be a protective factor against colorectal cancer. To explore the dose-response relationship in the associations between dietary calcium intake and colorectal cancer risk by cancer location, we conducted a case-control study among Korean population, whose dietary calcium intake levels are relatively low.

Methods: The colorectal cancer cases and controls were recruited from the National Cancer Center in Korea between August 2010 and August 2013. Information on dietary calcium intake was assessed using a semi-quantitative food frequency questionnaire and locations of the colorectal cancers were classified as proximal colon cancer, distal colon cancer, and rectal cancer. Binary and polytomous logistic regression models were used to evaluate the association between dietary calcium intake and risk of colorectal cancer.

Results: A total of 922 colorectal cancer cases and 2766 controls were included in the final analysis. Compared with the lowest calcium intake quartile, the highest quartile group showed a significantly reduced risk of colorectal cancer in both men and women. (Odds ratio (OR): 0.16, 95 \% confidence interval (CI): 0.11-0.24 for men; OR: 0.16, $95 \%$ Cl: 0.09-0.29 for women). Among the highest calcium intake groups, decrease in cancer risk was observed across all sub-sites of colorectum in both men and women.

Conclusion: In conclusion, calcium consumption was inversely related to colorectal cancer risk in Korean population where national average calcium intake level is relatively lower than Western countries. A decreased risk of colorectal cancer by calcium intake was observed in all sub-sites in men and women.
\end{abstract}

Keywords: Dietary Calcium, Colorectal Cancer, Sub-site Analysis, Case-control study, Korea

\section{Background}

Diet and nutrition are estimated to explain 30-50\% of the colorectal cancer incidences, which is the third most common cancer in men and the second most common in women worldwide [1,2]. Evidence from animal studies has suggested that high calcium intake may reduce the risk of colon cancer and recurrence of colorectal adenoma [3]. In addition, a pooled analysis of 10 cohort studies and meta-analyses of observational studies demonstrate the association between high calcium intake and reduced colorectal cancer risk in humans [4-7]. But in randomized clinical trial conducted

\footnotetext{
* Correspondence: shinaesun@snu.ac.kr; jskim@ncc.re.kr

${ }^{1}$ Department of Preventive Medicine, Seoul National University College of Medicine, 103 Daehakro, Jongno-gu 110-779Seoul, South Korea

${ }^{2}$ Molecular Epidemiology Branch, Research Institute, National Cancer Center, 323 Ilsan-ro, Ilsandong-gu, Goyang-si 410-769Gyeonggi-do, South Korea
} Full list of author information is available at the end of the article as a part of the Women's Health Initiative found no effect of calcium and vitamin D supplementation on colorectal cancer risk and meta-analysis of randomized controlled trials (RCTs) did not show statistically significant effects of calcium supplementation on colorectal cancer risk $[8,9]$. Therefore the level of evidence for dietary calcium on colorectal cancer prevention has been considered as "probable" [10].

Many of the previous studies were conducted in the western countries where dietary calcium levels are relatively higher than the Asian countries. Therefore, doseresponse relationship in low ranges of calcium intake and risk of colorectal cancer has been inadequately evaluated. In addition, pooled analysis of 10 cohort studies suggested a threshold effect of dietary calcium intake on colorectal cancer risk by showing little further reduction in colorectal cancer risk above $1000 \mathrm{mg} /$ day calcium 
intake [4]. Because previous calcium supplement trial participants showed high baseline levels of calcium intake over $750 \mathrm{mg} /$ day [6], effects of calcium supplementation on trial group could have been minimized in the RCTs. According to the fifth Korea National Health and Nutrition Examination Survey (KNHANES), mean calcium intake level among Koreans was only $507 \mathrm{mg} /$ day [11]. Therefore, study among Korean population may assess dose-response association of low level dietary calcium intake on the risk of colorectal cancer.

Descriptive epidemiologic studies have led to a hypothesis that proximal and distal colon cancers might have different risk factors [12-15]. Recent reports have demonstrated that proximal and distal colon cancers exhibit different clinical and biological characteristics [16-18]. A previous study in Korea reported that risk factors such as height, family history of cancer, alcohol consumption, and meat consumptions differed by colorectal cancer sub-sites [19]. In addition, few cohort studies conducted on different race and ethnicity did not show consistent association between dietary calcium and colorectal cancer risk by cancer location [20-25]. Although the pathogenesis of these differences by location is unclear, examining colorectal cancer by sub-sites and its association with dietary calcium intake may help to improve the knowledge of proximal, distal, and rectal cancer etiology.

Therefore, in this case-control study, we aimed to explore the dose-response relationship between dietary calcium intake and colorectal cancer risk in the Korean population, where national average calcium intake level is relatively lower than western countries. We also examined whether there are differences in the association between dietary calcium intake and the risk of colorectal cancer by sub-sites of colorectum.

\section{Methods}

\section{Study population}

Eligible colorectal cancer patients were recruited from the Center for Colorectal Cancer, National Cancer Center in Korea from August 2010 to August 2013. Among the 1427 eligible colorectal cancer patients who were hospitalized for an elective cancer surgery, 1259 patients were contacted, and 1070 agreed to participate in the study. Patients who did not complete a structured questionnaire were excluded and total 922 colorectal cancer patients remained in the final analysis. Eligible controls were recruited from participants who visited the Center for Early Detection and Prevention of the National Cancer Center in Korea for a health check-up program from March 2010 to November 2013. The health check-up program is provided bi-annually by the National Health Insurance Cooperation (NHIC), which covers entire Korean population including legal foreign residents, NHIC beneficiaries, and their dependents aged over 40. A total of 5936 participants completed the lifestyle questionnaire and food frequency questionnaire. Participants with implausible calorie intake $(<=500 \mathrm{kcal} /$ day or $>=4000 \mathrm{kcal} /$ day) were excluded in the analysis. Our initial plan was to match 2766 controls to 922 colorectal cancer patients by age groups and sex. However, due to large number of older cancer patients aged over 60 , we were unable to fully match age groups in men. All participants provided written informed consent to participate, and the study protocol was approved by the Institutional review board of the National Cancer Center (IRB No. NCCNCS-10-350).

\section{Variables}

Information on age, marital status, education level, cigarette smoking and alcohol drinking habits, household income, regular exercise and family history of cancer were obtained by a trained interviewer using a structured questionnaire. The locations of colorectal cancer were classified as proximal colon (C18.0-18.4), distal colon (C18.5-18.7), and rectum $(\mathrm{C} 19, \mathrm{C} 20)$ by using International Statistical Classification of Diseases and Related Health Problems 10th Revision [26]. Height and weight were measured before surgery for cases and during health examination for controls. Body Mass Index (BMI) was calculated as weight in kilograms divided by height in meters squares and used to define overweight (BMI $\geq 25)$. Engaging in regular exercise was considered if the participants underwent moderate physical activity at least once a week. Moderate physical activity was defined as " 3 or more days of vigorous activity in a week at least $20 \mathrm{~min} /$ day" or " 5 or more days of moderate-intensity activity and/or walking at least $30 \mathrm{~min} /$ day" or "any combination of walking, moderateintensity or vigorous intensity activities achieving a minimum of 600 MET-minutes/week". The regular dietary intake of each study participant was estimated by using a semi-quantitative food frequency questionnaire (SQFFQ). The reliability and validity of the food frequency questionnaire was demonstrated in a previous report [27]. The food frequency questionnaire consisted of 106 food items, and participants were asked to report the average frequencies and portion sizes of the foods they ate during the previous year. For each of the 106 food items, nutrient quantity per $100 \mathrm{~g}$ was calculated and converted to a daily nutrient intake. Dietary calcium intake was defined as calcium from food, not from supplements and the correlation coefficient between calcium intake from food frequency questionnaire and 12 days dietary records were $0.51-0.54$ in the prior validation study [27]. Dietary calcium from dairy foods or non-dairy foods was estimated. Computer-Aided Nutritional analysis Program (CANPro) version 3.0, 
which is a nutrient database developed by the Korean Nutrition Society, was used to estimate nutrients intakes.

\section{Statistical analysis}

To compare general characteristics between the cases and controls, chi-square tests were performed, and Cochran-Mantel-Haenszel chi-square tests were used to adjust for age. A residual method was used to adjust for individual total energy intake and adjusted dietary calcium intake were classified into sex-specific quartiles [28].

We used regression models to assess the association between daily dietary calcium intake and the risk of colorectal cancer. Age, marital status, educational level, household income, BMI, smoking status, alcohol consumption, regular exercise, and family history of cancer were selected as potential covariates based on literature review $[8,10,19]$. After applying the Cochran-MantelHaenszel chi-square test, only significant covariates $(p<$ 0.1 ) that predicted colorectal cancer risk were selected for the regression model after considering multi-colinearity. We also adjusted for dietary fiber intake and calcium supplement use [29]. In the final model, age, education level, regular exercise, fiber intake, calcium supplement use, and total energy intake by residual methods were included in the analysis. Binary and polytomous logistic regression models were used to calculate the odds ratios (OR) and their $95 \%$ confidence intervals (CI) for each quartile of calcium intake, and tests for trend were derived from logistic regression models with a single term representing the medians of each quartile group. For sensitivity analysis, the association was assessed among calcium supplement non-users.

To further visualize the association, we plotted daily dietary calcium intake and the risk of colorectal cancer stratified by sex and sub-sites using estimates from generalized additive models [30-32]. Effective degree of freedom (maximum 10) for the dietary calcium was automatically selected and applied to semi parametric models by mgcv package of $\mathrm{R}$ version 3.0.2 ( $\mathrm{R}$ foundation for Statistical Computing, Vienna, Austria).

All analyses were performed stratifying by sex, and SAS version 9.4 (SAS Institute Inc., Cary, NC) for used for main analyses.

\section{Results}

Basic characteristics and demographic descriptions of the study participants are presented in Table 1. There were 624 men and 298 women in the case group and 1872 men and 894 women in the control group. Among the men, differences in age groups, educational levels, household income, BMI, alcohol consumption, regular exercise, family history of cancer, colorectal cancer, and calcium supplementation use were observed between the colorectal cancer patients and controls. Among the women, differences in marital status, educational level, household income, smoking status, alcohol consumption, regular exercise, family history of cancer, and calcium supplementation use were observed between the colorectal cancer patients and controls. Mean dietary calcium intake among cases and controls was 463.7 and $450.8 \mathrm{mg} /$ day for men and 474.7 and $536.8 \mathrm{mg} /$ day for women, respectively. Top 3 main sources of dietary calcium were kimchi, tofu and milk (Additional file 1: Table S1).

The characteristics of the study subjects were also assessed by dietary calcium intake quartiles (Additional file 1: Table S2). Among the men, high calcium intake groups had higher educational levels, higher household income, and were more likely to engage in regular exercise. Among the women, high calcium intake groups had higher educational levels, were more likely to engage in regular exercise, and more likely to use calcium supplementation.

Table 2 shows the ORs and $95 \%$ CIs of colorectal cancer risk according to dietary calcium intake. High calcium consumption was inversely associated with colorectal cancer risk. Compared with the lowest quartile of calcium intake $(<335 \mathrm{mg} /$ day $)$, the multivariate odds ratio for colorectal cancer in the highest quartile of calcium intake $(\geq 567 \mathrm{mg} /$ day $)$ was 0.16 (95 \% CI: 0.11-0.24) in men. In women, the multivariate odds ratio for colorectal cancer was 0.16 (95 \% CI: 0.090.29 ) for the highest quartile of calcium intake ( $\geq 663 \mathrm{mg} /$ day) compared with the lowest quartile of calcium intake $(<380 \mathrm{mg} /$ day $)$.

In analysis considering sources of dietary calcium, both dairy and non-dairy food calcium showed negative association with risk of colorectal cancer. The highest dairy food calcium intake group showed a reduced risk of colorectal cancer in both men and women (OR: 0.28, 95 \% CI: $0.19-0.40$ for men; OR: 0.20, 95 \% CI: 0.120.35 for women). Similarly, the highest non-dairy food calcium intake group showed a reduced risk of colorectal cancer (OR: 0.16, 95 \% CI: $0.11-0.25$ for men; OR: $0.15,95$ \% CI: $0.08-0.27$ for women).

The odds ratios for colorectal cancer by sub-sites, according to dietary calcium intake are shown in Table 3. An inverse association between calcium intake and colorectal cancer risk persisted across all sub-sites of colorectum. The odds ratios for colorectal cancer for men in the highest quartile were 0.35 (95\% CI: 0.17-0.74) for the proximal colon cancer, 0.13 (95\% CI: 0.07-0.26) for the distal colon cancer, and 0.13 (95 \% CI: 0.08-0.23) for the rectal cancer compared with those in the lowest quartile. By comparing odds ratio of highest quartile across the sub-sites, prominent differences between 
Table 1 General characteristics of the study subjects, N (\%)

\begin{tabular}{|c|c|c|c|c|c|c|}
\hline & \multicolumn{3}{|c|}{ Men $(n=2496)$} & \multicolumn{3}{|c|}{ Women $(n=1192)$} \\
\hline & Case & Control & $P$-value ${ }^{a}$ & Case & Control & $P$-value \\
\hline & $(n=624)$ & $(n=1872)$ & & $(n=298)$ & $(n=894)$ & \\
\hline \multicolumn{7}{|l|}{ Age group (years) } \\
\hline-49 & $128(20.5)$ & $461(24.6)$ & $<0.001$ & $82(27.5)$ & $246(27.5)$ & $>0.999$ \\
\hline $50-59$ & $226(36.2)$ & $815(43.5)$ & & $111(37.3)$ & 333(37.3) & \\
\hline $60+$ & $270(43.3)$ & 596(31.8) & & 105(35.2) & $315(35.2)$ & \\
\hline \multicolumn{7}{|l|}{ Marital status } \\
\hline Married & $556(89.1)$ & $1671(89.3)$ & 0.262 & $216(72.5)$ & 697(78.0) & 0.028 \\
\hline Single & $66(10.6)$ & 167(8.9) & & $80(26.9)$ & 184(20.6) & \\
\hline Missing & $2(0.3)$ & $34(1.8)$ & & $2(0.7)$ & $13(1.5)$ & \\
\hline \multicolumn{7}{|l|}{ Education level } \\
\hline Less than middle school & 183(29.3) & 250(13.4) & $<0.001$ & 138(46.3) & $146(16.3)$ & $<0.001$ \\
\hline High school & $265(42.5)$ & 498(26.6) & & 103(34.6) & $365(40.8)$ & \\
\hline College or more & $176(28.2)$ & $1024(54.7)$ & & $57(19.1)$ & $332(37.1)$ & \\
\hline Missing & $0(0.0)$ & 100(5.3) & & $0(0.0)$ & $51(5.7)$ & \\
\hline \multicolumn{7}{|c|}{ Household income (10000 won/month) } \\
\hline$<200$ & 222(35.6) & 348(18.6) & $<0.001$ & 99(33.2) & 212(23.7) & 0.016 \\
\hline $200-400$ & 252(40.4) & 727(38.8) & & 134(45.0) & 313(35.0) & \\
\hline$>400$ & 150(24.0) & $588(31.4)$ & & $65(21.8)$ & $230(25.7)$ & \\
\hline Missing & $0(0.0)$ & 209(11.2) & & $0(0.0)$ & 139(15.6) & \\
\hline \multicolumn{7}{|l|}{ Body mass index $\left(\mathrm{kg} / \mathrm{m}^{2}\right)$} \\
\hline$<25$ & $431(69.1)$ & $1136(60.7)$ & $<0.001$ & $207(69.5)$ & $661(73.9)$ & 0.133 \\
\hline$\geq 25$ & 192(30.8) & 736(39.3) & & $91(30.5)$ & $233(26.1)$ & \\
\hline Missing & $1(0.2)$ & $0(0.0)$ & & $0(0.0)$ & $0(0.0)$ & \\
\hline \multicolumn{7}{|l|}{ Smoking status } \\
\hline Non-smoker & 145(23.2) & $391(20.9)$ & 0.418 & 264(88.6) & $854(95.5)$ & $<0.001$ \\
\hline Ex-smoker & $302(48.4)$ & $951(50.8)$ & & $15(5.0)$ & $21(2.4)$ & \\
\hline Current smoker & 177(28.4) & $530(28.3)$ & & $19(6.4)$ & $18(2.0)$ & \\
\hline Missing & $0(0.0)$ & $0(0.0)$ & & $0(0.0)$ & $1(0.1)$ & \\
\hline \multicolumn{7}{|l|}{ Alcohol consumption } \\
\hline Non-drinker & 107(17.2) & $308(16.5)$ & $<0.001$ & 172(57.7) & $567(63.4)$ & 0.031 \\
\hline Ex-drinker & $103(16.5)$ & 201(10.7) & & $26(8.7)$ & $44(4.9)$ & \\
\hline Current drinker & $414(66.4)$ & $1360(72.7)$ & & $100(33.5)$ & $282(31.5)$ & \\
\hline Missing & $0(0.0)$ & $3(0.2)$ & & $0(0.0)$ & $1(0.1)$ & \\
\hline \multicolumn{7}{|l|}{ Regular exercise } \\
\hline No & $388(62.2)$ & $786(42.0)$ & $<0.001$ & $225(75.5)$ & $403(45.1)$ & $<0.001$ \\
\hline Yes & 236(37.8) & 1073(57.3) & & $73(24.5)$ & $488(54.6)$ & \\
\hline Missing & $0(0.0)$ & $13(0.7)$ & & $0(0.0)$ & $3(0.3)$ & \\
\hline \multicolumn{7}{|l|}{ Family history of cancer } \\
\hline No & $391(62.7)$ & 1016(54.3) & $<0.001$ & $171(57.4)$ & $446(49.9)$ & 0.038 \\
\hline Yes & 233(37.3) & $846(45.2)$ & & $127(42.6)$ & $438(49.0)$ & \\
\hline Missing & $0(0.0)$ & $10(0.5)$ & & $0(0.0)$ & $10(1.1)$ & \\
\hline \multicolumn{7}{|c|}{ Family history of colorectal cancer } \\
\hline No & 559(89.6) & 1768(94.4) & $<0.001$ & 277(93.0) & 816(91.3) & 0.715 \\
\hline
\end{tabular}


Table 1 General characteristics of the study subjects, N (\%) (Continued)

\begin{tabular}{|c|c|c|c|c|c|c|}
\hline Yes & $65(10.4)$ & $94(5.0)$ & & $21(7.1)$ & $68(7.6)$ & \\
\hline Missing & $0(0.0)$ & $10(0.5)$ & & $0(0.0)$ & $10(1.1)$ & \\
\hline \multicolumn{7}{|l|}{ Calcium supplement use within 2 years } \\
\hline No & $621(99.5)$ & 1807(96.5) & $<0.001$ & 290(97.3) & 729(81.5) & $<0.001$ \\
\hline Yes & $3(0.5)$ & $65(3.5)$ & & $8(2.7)$ & $165(18.5)$ & \\
\hline Total energy intake (kcal/day), Mean (SD) & $2210.4(514.4)$ & 1811.4(553.4) & $<0.001$ & 1885.9(534.3) & 1674.3(604.4) & $<0.001$ \\
\hline Total calcium intake (mg/day), Mean (SD) & $463.7(211.2)$ & $450.8(248.6)$ & 0.207 & $474.7(248.0)$ & $536.8(335.1)$ & $<0.001$ \\
\hline
\end{tabular}

proximal colon and other sub-sites were observed. In case of women, the odds ratios for colorectal cancer in the highest quartile were 0.13 (95\% CI: 0.03-0.48) for the proximal colon cancer, 0.12 (95\% CI: 0.05-0.32) for the distal colon cancer, and 0.20 (95\% CI: 0.09-0.47) for the rectal cancer compared with those in the lowest quartile.

Figure 1 shows the relationship between daily dietary calcium intake and the risk of colorectal cancer in men and women. Figure 2 shows the relationship between dietary calcium intake and risk of colorectal cancer regarding colorectal cancer sub-sites in men and women. The Fig. 1 presents distinct patterns of colorectal cancer risk in relation to calcium intake; for example, the overall non-linear relationship between men and women was similar, showing a rapid decrease in the risk of colorectal cancer at calcium intake levels over $500 \mathrm{mg} /$ day and little further reduction in the risk when daily calcium intake exceeded more than $1000 \mathrm{mg} /$ day. (Test for nonlinearity, men: p-value <0.01; women: p-value $<0.01$ ) The overall spline analyses were concordant with the results from quartile analysis in Tables 2 and 3.

\section{Discussions}

In this case control study, we evaluated the doseresponse association between dietary calcium intake and risk of colorectal cancer. Compared with the lowest calcium intake quartile, the highest calcium intake quartile showed significantly reduced risk of colorectal cancer in both men and women. By applying a generalized additive model, both men and women showed a similar nonlinear relationship between dietary calcium intake and the risk of colorectal cancer. When dietary sources were considered, calcium intake from both dairy and nondairy food showed significant negative association with colorectal cancer risk.

According to the KNHANES data, the average daily calcium intake of Korean men and women was 561.0 and $452.6 \mathrm{mg}$, respectively, which was approximately $70 \%$ of the Korean recommended daily calcium allowance [11]. Daily calcium intake was inadequate in all age groups except for the infant period, and age groups over 65 only consumed $60 \%$ of their recommended daily allowance [11]. If there is a causal relationship between increased calcium intake and decreased colorectal cancer risk, colorectal cancer risk of Korean population may reduce by increasing the amounts of daily calcium consumption up to the recommended level (700$750 \mathrm{mg} /$ day).

There are biologically plausible mechanisms between dietary calcium intake and reduced colorectal cancer risks. Calcium plays protective role against inflammation and bile acid irritation on colonic wall. Intracellular calcium in colonic epithelial cells may reduce cancer promoting inflammatory responses [33], and the presence of ionized calcium may inhibit the toxic and potential irritating effects of fatty acids and free bile acid in the colon [34].

The sub-sites of the colon (proximal and distal) and rectum differs in embryonic origin, morphologic appearance, histologic features, and physiological functions [13, 35, 36]. Embryonically, proximal colon originates from midgut whereas distal and rectum originates from hindgut [36]. Main functions of proximal and distal colons are nutrient and water absorption, and that of rectum is fecal storage before defecation [36]. Wall of the rectum is thicker than colon, and proximal colon has more complex capillary network compared with distal colon and rectum [37, 38]. Distal colon possess high proportion of goblet cells and rectum has high proportion of endocrine cells $[39,40]$. Therefore due to various differences between colorectal sub-sites, dietary calcium effects on colorectal cancer risk may differ by cancer location. However, in our study, the association between colorectal cancer risk and daily calcium intake did not vary significantly by colorectal sub-sites. Only statistically significant differences were observed in the highest calcium intake group of men, showing more prominent cancer risk reduction in distal colon and rectum compared with proximal colon.

Few human studies have examined the association between calcium and cancer risk by sub-sites of the colorectum, but the results have been conflicting. In cohort study of Swedish men, multivariate rate ratio (RR) of colorectal cancer risk in the highest quartile calcium intake group (>=1445 mg/day) was 0.68 (95\% CI: 0.51 to 
Table 2 Odds ratios (OR) and $95 \%$ confidence intervals (Cl) for the association of dietary calcium intake and colorectal cancer risk

\begin{tabular}{|c|c|c|c|c|c|c|c|}
\hline & \multicolumn{3}{|l|}{ Male $(n=2496)$} & & \multicolumn{3}{|l|}{ Female $(n=1192)$} \\
\hline & Controls/ cases(n) & Age-adjusted OR(95\% Cl) & Multivariate $\mathrm{OR}^{\mathrm{a}}(95 \% \mathrm{Cl})$ & & Controls/cases(n) & Age-adjusted OR(95\% Cl) & Multivariate $\mathrm{OR}(95 \% \mathrm{Cl})$ \\
\hline Calcium intake (mg/day) & & & & Calcium intake (mg/day) & & & \\
\hline Q1 (<335) & $468 / 202$ & 1.00 & 1.00 & Q1 (<380) & $224 / 125$ & 1.00 & 1.00 \\
\hline Q2 (335 - < 432) & $468 / 222$ & $1.09(0.86-1.37)$ & $0.92(0.71-1.19)$ & Q2 (380 - < 519) & $223 / 111$ & $0.89(0.65-1.23)$ & $0.93(0.65-1.34)$ \\
\hline Q3 $(432-<567)$ & $468 / 141$ & $0.68(0.52-0.87)$ & $0.51(0.38-0.68)$ & Q3 (519-<663) & $223 / 43$ & $0.34(0.23-0.51)$ & $0.39(0.25-0.61)$ \\
\hline Q4 ( $\geq 567)$ & $468 / 59$ & $0.28(0.20-0.38)$ & $0.16(0.11-0.24)$ & Q4 ( $(2663)$ & $224 / 19$ & $0.15(0.09-0.25)$ & $0.16(0.09-0.29)$ \\
\hline P-value for trend ${ }^{b}$ & & $<0.001$ & $<0.001$ & P-value for trend & & $<0.001$ & $<0.001$ \\
\hline $\begin{array}{l}\text { Dairy food calcium } \\
\text { (mg/day) }\end{array}$ & & & & $\begin{array}{l}\text { Dairy food calcium } \\
\text { (mg/day) }\end{array}$ & & & \\
\hline Q1 $(<11)$ & $468 / 228$ & 1.00 & 1.00 & Q1 $(<20)$ & $223 / 109$ & 1.00 & 1.00 \\
\hline Q2 $(11-<47)$ & $468 / 222$ & $0.98(0.78-1.23)$ & $1.02(0.80-1.30)$ & Q2 (20 - < 78) & $224 / 102$ & $0.93(0.67-1.29)$ & $1.01(0.70-1.47)$ \\
\hline Q3 (47 - < 146) & $468 / 125$ & $0.55(0.43-0.71)$ & $0.65(0.49-0.85)$ & Q3 $(78-<225)$ & $224 / 64$ & $0.59(0.41-0.84)$ & $0.67(0.45-1.01)$ \\
\hline Q4 ( $\geq 146)$ & $468 / 49$ & $0.21(0.15-0.29)$ & $0.28(0.19-0.40)$ & Q4 ( $\geq 225)$ & $223 / 23$ & $0.21(0.13-0.34)$ & $0.20(0.12-0.35)$ \\
\hline P-value for trend & & $<.001$ & $<.001$ & P-value for trend & & $<0.001$ & $<0.001$ \\
\hline $\begin{array}{l}\text { Non-Dairy food calcium } \\
\text { (mg/day) }\end{array}$ & & & & $\begin{array}{l}\text { Non-Dairy food calcium } \\
\text { (mg/day) }\end{array}$ & & & \\
\hline Q1 (<279) & $468 / 168$ & 1.00 & 1.00 & Q1 (<302) & $224 / 111$ & 1.00 & 1.00 \\
\hline Q2 $(279-<360)$ & $468 / 230$ & $1.33(1.04-1.68)$ & $1.07(0.82-1.40)$ & Q2 (302 - < 397) & $223 / 109$ & $0.98(0.71-1.35)$ & $0.89(0.61-1.29)$ \\
\hline Q3 $(360-<470)$ & $468 / 159$ & $0.91(0.70-1.17)$ & $0.59(0.44-0.80)$ & Q3 (397 - < 522) & $223 / 58$ & $0.52(0.36-0.75)$ & $0.53(0.35-0.82)$ \\
\hline Q4 ( $\geq 470)$ & $468 / 66$ & $0.37(0.27-0.50)$ & $0.16(0.11-0.25)$ & Q4 ( $\geq 522)$ & $224 / 20$ & $0.18(0.11-0.30)$ & $0.15(0.08-0.27)$ \\
\hline P-value for trend & & $<0.001$ & $<0.001$ & P-value for trend & & $<0.001$ & $<0.001$ \\
\hline
\end{tabular}

adjusted by age, education level, regular exercise, fiber intake, calcium supplement use, and total energy intake

${ }^{\mathrm{b}}$ Test for trend calculated with the median intake for each category of dietary calcium intake as a continuous variable 
Table 3 Odds ratios (OR) and $95 \%$ confidence intervals (Cl) for the association of dietary calcium intake and colorectal cancer sub-sites

\begin{tabular}{|c|c|c|c|c|c|c|c|c|c|c|}
\hline & Control & Proximal & colon & & Distal col & & & Rectum & & \\
\hline $\begin{array}{l}\text { Total energy adjusted } \\
\text { dietary calcium intake } \\
\text { (mg/day) }\end{array}$ & No & No & $\begin{array}{l}\text { Age-adjusted OR } \\
(95 \% \mathrm{Cl})\end{array}$ & $\begin{array}{l}\text { Multivariate } \mathrm{OR}^{\mathrm{a}} \\
(95 \% \mathrm{Cl})\end{array}$ & No & Age-adjusted OR(95\% Cl) & Multivariate OR(95\% Cl) & No & $\begin{array}{l}\text { Age-adjusted OR } \\
(95 \% \mathrm{Cl})\end{array}$ & $\begin{array}{l}\text { Multivariate OR } \\
(95 \% \mathrm{Cl})\end{array}$ \\
\hline Men & $N=1872$ & $N=113$ & & & $N=178$ & & & $N=320$ & & \\
\hline Q1 (<335) & 468 & 26 & 1.00 & 1.00 & 60 & 1.00 & 1.00 & 109 & 1.00 & 1.00 \\
\hline Q2 (335 - < 432) & 468 & 43 & $1.63(0.99-2.70)$ & $1.40(0.83-2.37)$ & 63 & $1.04(0.71-1.51)$ & $0.90(0.60-1.34)$ & 112 & $1.02(0.76-1.36)$ & $0.85(0.61-1.17)$ \\
\hline Q3 $(432-<567)$ & 468 & 28 & $1.04(0.60-1.80)$ & $0.81(0.45-1.45)$ & 41 & $0.66(0.43-1.00)$ & $0.51(0.33-0.81)$ & 71 & $0.63(0.45-0.87)$ & $0.47(0.32-0.67)$ \\
\hline Q4 ( $\geq 567)$ & 468 & 16 & $0.58(0.31-1.10)$ & $0.35(0.17-0.74)$ & 14 & $0.22(0.12-0.40)$ & $0.13(0.07-0.26)^{c}$ & 28 & $0.25(0.16-0.38)$ & $0.13(0.08-0.23)^{c}$ \\
\hline P-value for trend ${ }^{b}$ & & & 0.021 & $<0.001$ & & $<0.001$ & $<0.001$ & & $<0.001$ & $<0.001$ \\
\hline Women & $N=894$ & $N=53$ & & & $N=113$ & & & $N=124$ & & \\
\hline Q1 (<380) & 224 & 26 & 1.00 & 1.00 & 43 & 1.00 & 1.00 & 51 & 1.00 & 1.00 \\
\hline Q2 (380 - < 519) & 223 & 18 & $0.70(0.37-1.32)$ & $0.75(0.39-1.46)$ & 48 & $1.12(0.72-1.76)$ & $1.11(0.68-1.81)$ & 43 & $0.85(0.54-1.33)$ & $0.93(0.58-1.52)$ \\
\hline Q3 (519 - <663) & 223 & 6 & $0.23(0.09-0.57)$ & $0.27(0.11-0.72)$ & 15 & $0.35(0.19-0.65)$ & $0.35(0.18-0.68)$ & 22 & $0.43(0.25-0.74)$ & $0.55(0.31-0.99)$ \\
\hline Q4 ( $\geq 663)$ & 224 & 3 & $0.11(0.03-0.38)$ & $0.13(0.03-0.48)$ & 7 & $0.16(0.07-0.37)$ & $0.12(0.05-0.32)$ & 8 & $0.16(0.07-0.34)$ & $0.20(0.09-0.47)$ \\
\hline P-value for trend & & & $<0.001$ & 0.001 & & $<0.001$ & $<0.001$ & & $<0.001$ & $<0.001$ \\
\hline
\end{tabular}

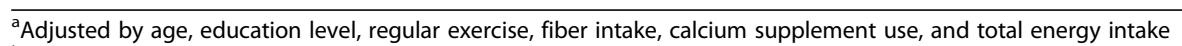

${ }^{\mathrm{b}}$ Test for trend calculated with the median intake for each category of dietary calcium intake as a continuous variable

'The odds ratio was statistically different from that of proximal colon ( $p=0.05$ for distal colon and $p=0.03$ for rectum) 

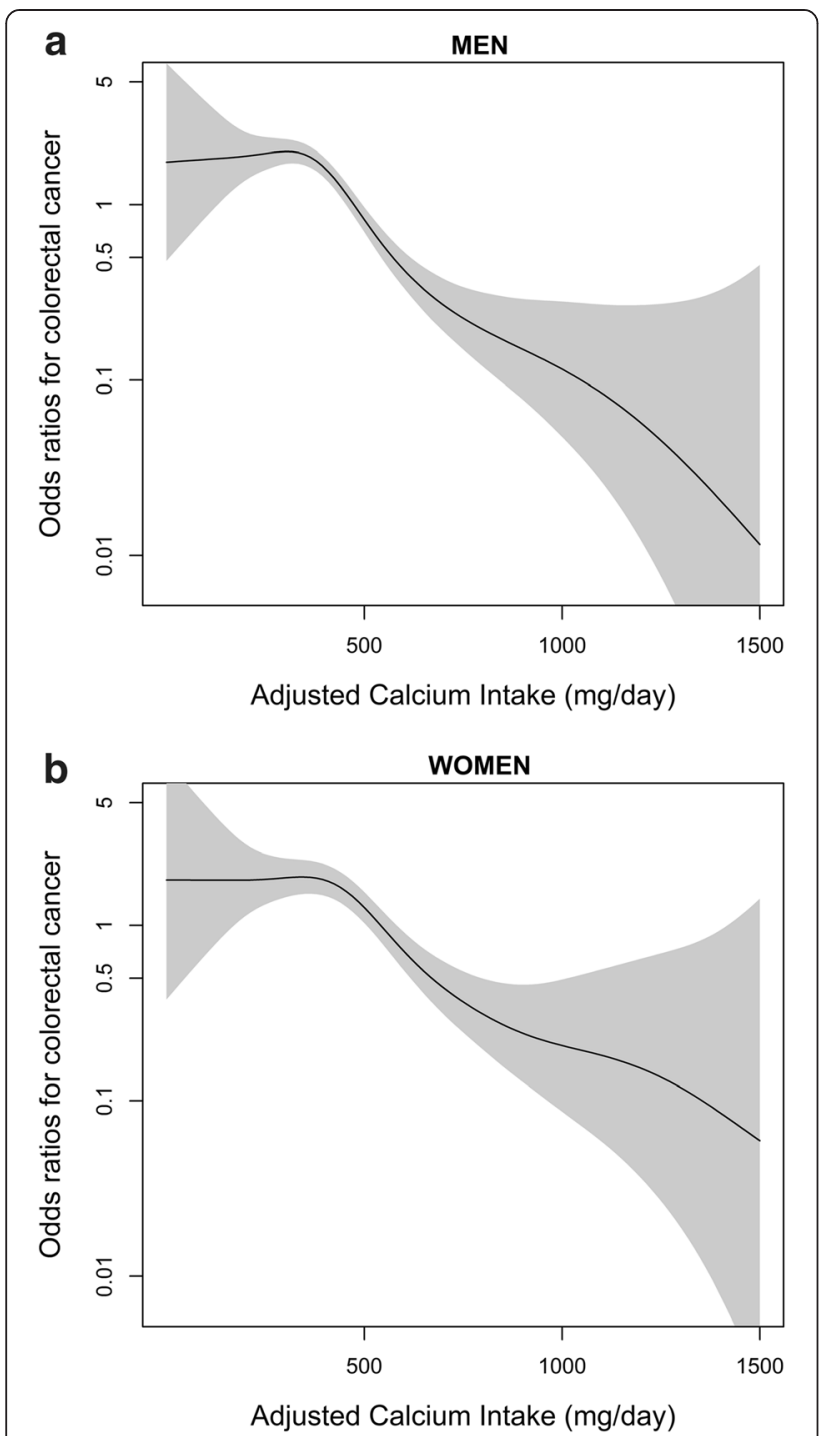

Fig. 1 Relationship between total energy adjusted daily calcium intake (mg/day) and colorectal cancer risk. a Men. b Women. Each figure shows the spline curve (solid line) with a $95 \% \mathrm{Cl}$ (shaded). The curves are adjusted for age, education level, regular exercise, fiber intake, calcium supplement use, and total energy intake

0.91) compared to lowest quartile calcium intake group (<956 mg/day). In sub-site analysis, proximal colon and rectum showed a significant decrease in cancer risk with high intake of dietary calcium [20]. In cohort study conducted in the United States, the highest quintile calcium intake group ( $>=1255 \mathrm{mg} /$ day) showed marginally reduced risk of colorectal cancer in men and women compared to the lowest quintile calcium intake group (<561 mg/day) (RR: 0.87, 95 \% CI: 0.67-1.12) [21]. In sub-site analysis, only proximal colon showed marginally reduced risk (RR: 0.57, 95 \% CI: $0.28-1.13$ ) of colorectal cancer among the highest quintile calcium intake group in men. In cohort study of women, the highest quintile intake group ( $>=830.9 \mathrm{mg} /$ day) showed statistically significant reduction of colorectal cancer risk compared to the lowest calcium intake group $(<412.3 \mathrm{mg} /$ day) (RR: 0.74, 95 \% CI: 0.56-0.98) [22], and the risk reduction was only observed for proximal colon in sub-site analysis (RR: 0.60, 95 \% CI: 0.38-0.97). In Swedish mammography cohort, women aged over 55 with the highest calcium intake $(>=816 \mathrm{mg} /$ day $)$ showed decreased colorectal cancer risk compared to the lowest quartile intake group ( $<568 \mathrm{mg} /$ day) for overall colorectal cancer (RR: 0.66, 95 \% CI: 0.49-0.89) [23], and distal colon cancer (RR: 0.33, 95 \% CI: 0.16-0.67). In addition, although total calcium intake was inversely associated with distal colon cancer in pooled analysis of two cohort studies [24], there was no significant association between dietary calcium and colorectal sub-sites in Japanese cohort study [25]. Compared to previous studies, our study participant's daily calcium intake levels are relatively low. Because marked reduction of colorectal cancer risk in all sub-sites of colorectum has been showed in our study results, dose-response relationship in lower ranges of calcium intake could be suggested from our study.

There are several strengths of our study. First, the association between dietary calcium intake and colorectal cancer risks are analyzed among Korean population, whose average calcium intake is relatively lower than western population. Therefore, assessment of doseresponse relationship within low level dietary calcium on risk of colorectal cancer could be made with our analyses. Second, not only the dose-response relationship but also potential differences in risk among sub-sites of colorectum could be assessed in our study. By using graphical methods, we compared patterns of colorectal cancer risk according to dietary calcium intake by each colorectal sub-sites.

Our main limitation comes from the study design and the use of the food frequency questionnaire. First, the controls were recruited from the participants of the health check-up program provided by the National Health Insurance Corporation; therefore, they could have a healthier lifestyle than the colorectal cancer cases. However, since the cases and controls were recruited in the same hospital, characteristics between two groups would be comparable. Second, recall bias is inevitable due to case control study design assessing for prior personal information. However, since dietary calcium intake was estimated from diverse food sources, it is hard to speculate that the cases or controls systematically underor over reported their calcium intake levels. Third, due to food frequency questionnaire use in our study, potential measurement errors could have affected our study results. The non-differential measurement error, however, would lead the results toward the null values. Fourth, although we asked the study participants to 

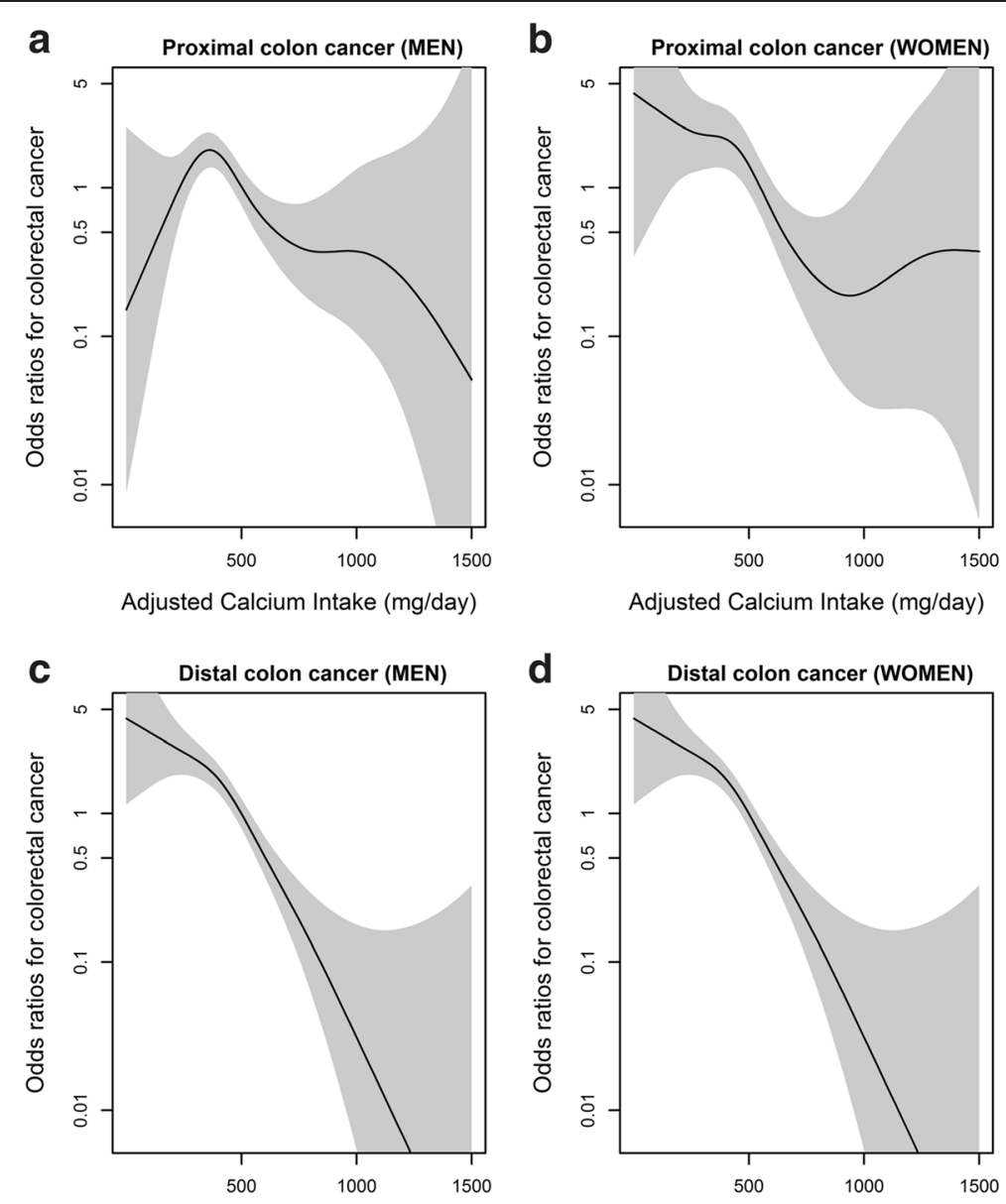

Adjusted Calcium Intake (mg/day)

Adjusted Calcium Intake (mg/day)
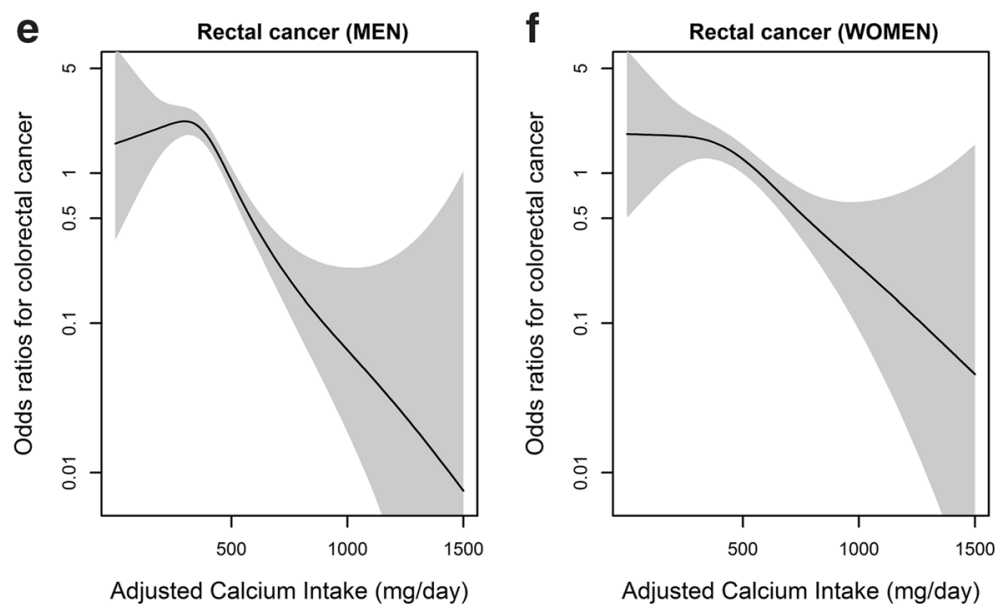

Adjusted Calcium Intake (mg/day)

Fig. 2 Relationship between total energy adjusted daily calcium intake (mg/day) and colorectal cancer risk in men and women stratified by cancer sub-sites. a Proximal colon cancer (Men). b Proximal colon cancer (Women). c Distal colon cancer (Men). d Distal colon cancer (Women), e Rectal cancer (Men). f Rectal cancer (Women). Each figure shows the spline curve (solid line) with a $95 \% \mathrm{Cl}$ (shaded). The curves are adjusted for age, education level, regular exercise, fiber intake, calcium supplement use, and total energy intake

report their food consuming patterns before cancer diagnosis, direct causal inference between dietary calcium consumption and risk reduction of colorectal cancer cannot be made in case-control study design. Fifth, vitamin D intake, which could be a potential confounder, could not be estimated from the nutrients database we 
used. Lastly, although information on calcium supplementation use during last 2 years were available, we did not ask the dose of calcium supplement that participants consumed. Therefore total calcium intake could not be estimated. However, in sensitivity analysis conducted for participants who did not consume calcium supplements, the association was very similar to the main analysis (Additional file 1: Table S3). In addition, since the proportion of supplement consumers was higher in controls than in cases, the analysis of total intake of calcium would reinforce our findings.

\section{Conclusions}

In conclusion, calcium consumption was inversely related to colorectal cancer risk in Korean population where national average calcium intake level is relatively lower than western countries. A decreased risk of colorectal cancer by calcium intake was observed in all subsites of men and women.

\section{Additional file}

Additional file 1: Table S1. Top 10 calcium contributing foods of study population (mg/day). Table S2. Characteristics of study subjects according to quartile of energy-adjusted dietary calcium intake $\mathrm{N}(\%)$. Table S3. Odds ratios (OR) and 95\% confidence intervals (Cl) for the association of dietary calcium intake and colorectal cancer risk among the calcium supplement non-users. (DOC $129 \mathrm{~kb})$

\section{Competing interests}

The authors declare that they have no competing interests.

\section{Author's contributions}

$\mathrm{AS}, \mathrm{JHO}$, and $\mathrm{JK}$ conceived and designed the study; JL, JWP, and JHO contributed patients recruitment and data collection; JHL, CH and JL analyzed the data; AS and $\mathrm{CH}$ drafted the manuscript; All authors critically reviewed the manuscript and approved the final version.

\section{Acknowledgement}

This study was supported by the Basic Science Research Program through the National Research Foundation of Korea (2010-0010276 and 2013R1A1A2A10008260) and National Cancer Center Korea (0910220 and 1210141).

\section{Author details}

${ }^{1}$ Department of Preventive Medicine, Seoul National University College of Medicine, 103 Daehakro, Jongno-gu 110-779Seoul, South Korea. ${ }^{2}$ Molecular Epidemiology Branch, Research Institute, National Cancer Center, 323 Ilsan-ro, Ilsandong-gu, Goyang-si 410-769Gyeonggi-do, South Korea. ${ }^{3}$ Center for Colorectal Cancer, National Cancer Center, Goyang-si, Republic of Korea. ${ }^{4}$ Department of Surgery, Seoul National University College of Medicine, Seoul, Republic of Korea. ${ }^{5}$ Department of Nutritional Science and Food Management, Ewha Womans University, Seoul, Republic of Korea.

Received: 21 August 2015 Accepted: 20 November 2015 Published online: 16 December 2015

\section{References}

1. Ferlay J, Soerjomataram I, Ervik M, Dikshit R, Eser S, Mathers C, et al. GLOBOCAN 2012 v1. 0, cancer incidence and mortality worldwide: IARC CancerBase No. 11 [internet]. Lyon: International Agency for Research on Cancer; 2014.
2. Vargas AJ, Thompson PA. Diet and nutrient factors in colorectal cancer risk. Nutr Clin Pract. 2012;27(5):613-23.

3. Lipkin M. Preclinical and early human studies of calcium and colon cancer prevention. Ann N Y Acad Sci. 1999;889:120-7.

4. Cho E, Smith-Warner SA, Spiegelman D, Beeson WL, van den Brandt PA, Colditz GA, et al. Dairy foods, calcium, and colorectal cancer: a pooled analysis of 10 cohort studies. J Natl Cancer Inst. 2004;96(13):1015-22.

5. Huncharek M, Muscat J, Kupelnick B. Colorectal cancer risk and dietary intake of calcium, vitamin $D$, and dairy products: a meta-analysis of 26,335 cases from 60 observational studies. Nutr Cancer. 2009;61(1):47-69.

6. Keum N, Aune D, Greenwood DC, Ju W, Giovannucci EL. Calcium intake and colorectal cancer risk: Dose-response meta analysis of prospective observational studies. Int J Cancer. 2014;135(8):1940-8.

7. Heine Bröring RC, Winkels RM, Renkema J, Kragt L, Orten Luiten ACB, Tigchelaar EF, et al. Dietary supplement use and colorectal cancer risk: a systematic review and meta analyses of prospective cohort studies. Int J Cancer. 2015;136(10):2388-401.

8. Wactawski-Wende J, Kotchen JM, Anderson GL, Assaf AR, Brunner RL, O'Sullivan MJ, et al. Calcium plus vitamin D supplementation and the risk of colorectal cancer. N Engl J Med. 2006;354(7):684-96.

9. Bristow SM, Bolland MJ, MacLennan GS, Avenell A, Grey A, Gamble GD, et al. Calcium supplements and cancer risk: a meta-analysis of randomised controlled trials. Br J Nutr. 2013:110(8):1384-93.

10. World Cancer Research Fund/American Institute for Cancer Research. Food, nutrition, physical activity and the prevention of colorectal cancer, Continuous update project report summary. 2011.

11. Hu J, La Vecchia C, Augustin LS, Negri E, de Groh M, Morrison H, et al. Glycemic index, glycemic load and cancer risk. Ann Oncol: Off J Euro Soc Med Oncol. 2013;24(1):245-51.

12. Bonithon-Kopp C, Benhamiche AM. Are there several colorectal cancers? Epidemiological data. Eur J Cancer Prev. 1999;8 Suppl 1:S3-S12.

13. Bufill JA. Colorectal cancer: evidence for distinct genetic categories based on proximal or distal tumor location. Ann Intern Med. 1990;113(10):779-88.

14. Ponz de Leon M, Sacchetti C, Sassatelli R, Zanghieri G, Roncucci L, Scalmati A. Evidence for the existence of different types of large bowel tumor: suggestions from the clinical data of a population-based registry. I Surg Oncol. 1990;44(1):35-43.

15. Pocard M, Salmon RJ, Muleris M, Remvikos Y, Bara J, Dutrillaux B, et al. Two colons-two cancers? proximal or distal adenocarcinoma: arguments for a different carcinogenesis. Bull Cancer. 1995;82(1):10-21.

16. Distler P, Holt PR. Are right- and left-sided colon neoplasms distinct tumors? Dig Dis. 1997;15(4-5):302-11.

17. lacopetta B. Are there two sides to colorectal cancer? Int J Cancer. 2002;101(5):403-8.

18. Gonzalez EC, Roetzheim RG, Ferrante JM, Campbell R. Predictors of proximal vs. distal colorectal cancers. Dis Colon Rectum. 2001;44(2):251-8.

19. Shin A, Joo J, Bak J, Yang HR, Kim J, Park S, et al. Site-specific risk factors for colorectal cancer in a Korean population. PLoS One. 2011;6(8):e23196.

20. Larsson SC, Bergkvist L, Rutegard J, Giovannucci E, Wolk A. Calcium and dairy food intakes are inversely associated with colorectal cancer risk in the Cohort of Swedish Men. Am J Clin Nutr. 2006;83(3):667-73. quiz 728-9.

21. McCullough ML, Robertson AS, Rodriguez C, Jacobs EJ, Chao A, Carolyn J, et al. Calcium, vitamin D, dairy products, and risk of colorectal cancer in the cancer prevention study II nutrition cohort (United States). Cancer Causes Control. 2003;14(1):1-12.

22. Flood A, Peters U, Chatterjee N, Lacey Jr JV, Schairer C, Schatzkin A. Calcium from diet and supplements is associated with reduced risk of colorectal cancer in a prospective cohort of women. Cancer Epidemiol Biomarkers Prev. 2005;14(1):126-32.

23. Terry P, Baron JA, Bergkvist L, Holmberg L, Wolk A. Dietary calcium and vitamin $D$ intake and risk of colorectal cancer: a prospective cohort study in women. Nutr Cancer. 2002;43(1):39-46.

24. Wu K, Willett WC, Fuchs CS, Colditz GA, Giovannucci EL. Calcium intake and risk of colon cancer in women and men. J Natl Cancer Inst. 2002;94(6):437-46.

25. Ishihara J, Inoue M, Iwasaki M, Sasazuki S, Tsugane S. Dietary calcium, vitamin D, and the risk of colorectal cancer. Am J Clin Nutr. 2008;88(6):1576-83.

26. World Health Organization. International statistical classification of diseases and related health problems. Geneva: World Health Organization; 2004.

27. Ahn Y, Kwon E, Shim JE, Park MK, Joo Y, Kimm K, et al. Validation and reproducibility of food frequency questionnaire for Korean genome epidemiologic study. Eur J Clin Nutr. 2007;61(12):1435-41. 
28. Willett WC, Howe GR, Kushi LH. Adjustment for total energy intake in epidemiologic studies. Am J Clin Nutr. 1997;65(4):1220S-8S.

29. Sanjoaquin MA, Allen N, Couto E, Roddam AW, Key TJ. Folate intake and colorectal cancer risk: a meta analytical approach. Int J Cancer. 2005;113(5):825-8.

30. Hastie T, Tibshirani R. Generalized additive models for medical research. Stat Methods Med Res. 1995;4(3):187-96.

31. Campbell I, Hastie T, Tibshiram R. Usefulness of generalized additive models. Stat Methods Med Res. 1996;5(3):331-2.

32. Wood S. Generalized additive models: an introduction with R: CRC press. 2006.

33. Garland CF, Garland FC. Do sunlight and vitamin D reduce the likelihood of colon cancer? Int J Epidemiol. 1980;9(3):227-31.

34. Newmark HL, Wargovich MJ, Bruce WR. Colon cancer and dietary fat, phosphate, and calcium: a hypothesis. J Natl Cancer Inst. 1984;72(6):1323-5.

35. McMichael AJ, Potter JD. Host factors in carcinogenesis: certain bile-acid metabolic profiles that selectively increase the risk of proximal colon cancer. J Natl Cancer Inst. 1985;75(2):185-91.

36. Li FY, Lai MD. Colorectal cancer, one entity or three. J Zhejiang Univ Sci B. 2009;10(3):219-29.

37. Araki K, Furuya Y, Kobayashi M, Matsuura K, Ogata T, Isozaki H. Comparison of mucosal microvasculature between the proximal and distal human colon. J Electron Microsc. 1996:45(3):202-6.

38. Skinner SA, O'Brien PE. The microvascular structure of the normal colon in rats and humans. J Surg Res. 1996;61(2):482-90.

39. Arai T, Kino I. Morphometrical and cell kinetic studies of normal human colorectal mucosa. Pathol Int. 1989;39(11):725-30.

40. Shamsuddin AM, Phelps PC, Trump BF. Human large intestinal epithelium: light microscopy, histochemistry, and ultrastructure. Human Pathol. 1982;13(9):790-803.

\section{Submit your next manuscript to BioMed Central and we will help you at every step:}

- We accept pre-submission inquiries

- Our selector tool helps you to find the most relevant journal

- We provide round the clock customer support

- Convenient online submission

- Thorough peer review

- Inclusion in PubMed and all major indexing services

- Maximum visibility for your research 